\title{
Discovering the value of personality types in communication training for pharmacy students
}

\author{
M J Eksteen, BPharm, MPharm; M J Basson, BSc HED Hons, BSc, MSc \\ Department of Pharmacy Practice, School of Pharmacy, Faculty of Health Sciences, Potchefstroom Campus, North-West University, Potchefstroom, South Africa
}

Corresponding author: M J Basson (marietta.basson@nwu.ac.za)

Background. The current movement in the pharmacy profession, from the product towards the patient, demands new educational approaches that support the exit-level outcomes of the South African Pharmacy Council as implemented in 2013. Patient-centred communication calls for an ability to 'walk in the patients' shoes'. Pharmacists, like others, are naturally inclined to think and treat others as they themselves perceive the world, which can result in miscommunication.

Objectives. To determine the prevalence of the 16 different Myers-Briggs Type Indicator ${ }^{\circledR}$ (MBTI ${ }^{\circledR}$ ) communication styles, and compare them with the prevalence of these styles in the South African (SA) population. Furthermore, to determine the possibility of a pharmacy student interacting with a patient with a similar communication style.

Method. A novel way to sensitise pharmacists to the differences in people's experiences, behaviours and communication styles is to introduce them to type theory with the $\mathrm{MBTI}^{\circledR}$. A survey design was used to determine 786 pharmacy students' communication styles, using the MBTI ${ }^{\circledR}$. These students were enrolled for the subject 'Communication for pharmacists' at the largest pharmacy school in SA.

Results. More students were consistently found with Sensing Feeling preferences than in the general SA population. The possibility that a pharmacy student might consult with a patient with a similar style varied between one and 414 chances out of 10000 consultations.

Conclusion. This study highlights the importance and possibility of using the MBTI ${ }^{\circledR}$ as part of communication training of pharmacy students. Sensitising students to their own preferences and those of their patients empowers them to patient-centred communication.

Afr J Health Professions Educ 2015;7(1):43-46. DOI:10.7196/AJHPE.370

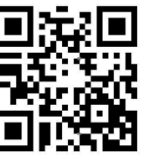

Patient-centredness requires pharmacists to view their patients as individuals with unique experiences. ${ }^{[1]}$ Each patient in their social context responds uniquely to verbal communication. Traditionally, pharmacists have been regarded as dispensers of prescription medication. ${ }^{[2]}$ They were trained to understand medication, focus on the product and give product information as the main approach to patients, and emphasise medication adherence as a goal. The move in the profession from product orientation (dispensing medication) to patient orientation requires expanding of their professional training. ${ }^{[3]}$ The pharmacist's professional role has matured to include provision of information, education, and pharmaceutical care services. This expanded role encapsulates a collaborative pharmacist-patient relationship in which both have roles and responsibilities. ${ }^{[4]}$ To be patient-centred, pharmacists need to learn new ways of being with their patients and talking to them, which involves new knowledge and skills as well as innovative ideas to advance the profession towards this role.

Communication is mentioned in six of the 10 Competence Standards identified by the South African Pharmacy Council, which together form the minimum requirements for an entry-level pharmacist to be registered in South Africa (SA) ${ }^{[5]}$ Developed communication skills are essential for the practising pharmacist and non-negotiable in building provider-patient relationships. Effective communication is at the heart of patient safety and optimal health outcomes. ${ }^{\left[{ }^{[6]}\right.}$ Training pharmacists to be more aware of the impact of their natural communication style on their patients ${ }^{[7]}$ and healthcare colleagues empowers them to move their professional role from product to patient focused. Such awareness may prompt pharmacists to develop their interpersonal skills to address the human-centred elements of patient-centredness. The more advanced the communication skills of a pharmacist, the better he is equipped to assist patients. ${ }^{[8]}$
Personality type is an indicator of communication style and the MyersBriggs Type Indicator ${ }^{\circledR}\left(\mathrm{MBTI}^{\circledR}\right)$ is an instrument based on the work of Carl Jung. According to the personality type framework, two people of the same type have the least chance of miscommunication. Consider the four bipolar preference pairs $^{[9]}$ of the MBTI $^{\circledR}$ :

- Extroversion (E) and Introversion (I). A focus on and energy from the outer world of people and activity $\mathrm{v}$. a preference for an inner world of thoughts and feelings.

- Sensing (S) and Intuition (N). A practical focus on facts and detail v. attention to patterns and possibilities.

- Thinking (T) and Feeling (F). A focus on logic and analysis v. personal values and priorities.

- Judging (J) and Perceiving (P). A tendency for decisiveness and preference for structure and control v. a tendency to keep options open and a preference for spontaneity and flexibility.

A person is naturally inclined to prefer one of the preferences in each pair, which is usually better developed. This choice gives rise to a preference combination or personality type. The 16 personality type combinations are each associated with habitual preferences and behaviours.

The MBTI ${ }^{\circledR}$ is normally used in education to develop teaching methods that will meet the needs of the different types and to understand differences in motivation for learning. In communication training, the $\mathrm{MBTI}^{\circledR}$ is regularly applied to learn approaches that are most likely to lead to agreement and co-operation, increase understanding by 'talking the language' of different types, and create a climate where differences are seen as valuable. ${ }^{[9]}$

For the first time in pharmacy education, personality types were used as a non-judgemental tool that offers a framework to sensitise pharmacy 
students to their own communication style preference and its effect on their patients. ${ }^{[9]}$ Using the $\mathrm{MBTI}^{\circledR}$ as part of the communication training of pharmacy students gives them the opportunity to appreciate and understand the differences between them as professionals and them and their patients. In this project, the $\mathrm{MBTI}^{\circledR}$ was included in the training of pharmacists to empower them on their way to patient-centred care. More importantly, over the long term, pharmacy students will form better relationships with their patients, which in turn will result in improved medication adherence rates. This study identified the prevalence of the different communication styles among pharmacy students and determined the possibility of their interacting with a patient with a similar communication style.

\section{Method}

This study is part of a larger project on teaching communication to pharmacy students. All students at a higher education training institution in SA, who enrolled from 2007 to 2012 for the semester subject 'Communication for pharmacists', were part of the study population. As part of their training, they took the $\mathrm{MBTI}^{\circledR}$ under supervision of a registered user. ${ }^{[9]}$ The results were verified through workshops where students experienced the communication implications of their preferences in their future line of work. They also became aware of the implications of communication preferences other than their own.

A survey design was used in this study. The information was collected for each group at the beginning of the semester subject and is used here to describe the study population at that single point in time. Form G of the $\mathrm{MBTI}^{\circledR}$, a paper and pencil Jungian-based inventory, was used as the measuring instrument. It consists of 126 items that measure the four bipolar preference pairs.

Descriptive statistics were used to describe the fourth-year students of 2007 - 2012 and compare them with the SA population in terms of the four bipolar preference pairs. In 2012, owing to a curriculum change, the communication course moved from the fourth to the third year and we had an opportunity to evaluate both year groups in one year. The third-year students (2012) were described and compared with the fourth-year students in the same year to establish whether the same pattern holds. Finally, the probability that a pharmacy student will interact with a patient of a similar preference type, was calculated for the fourth-year students from 2007 to 2012 and the third-year students of 2012. To calculate the probability for equally likely outcomes, the probability $(p)$ that an event occurs equals the number of favourable events divided by the number of possible events. For independent events, the probability that both events will happen equals $p$ (event A) multiplied by $p$ (event B). ${ }^{[10]}$

The $\mathrm{MBTI}^{\circledR}$ was used primarily as a teaching tool and the data for this project were analysed long after the students completed 'Communication for pharmacists'. The students' names and numbers did not form part of the data analysed; therefore, no individual could be identified or implicated in the summary analysis. The project was executed by a registered MBTI ${ }^{\circledR}$ user, especially the data collection and the verification of the results with the participants.

The scope of this study was limited to the preferences of pharmacy students at a single pharmacy school in SA - the largest pharmacy school in the country ${ }^{[11]}$ - and could form the basis for a broader, national research project from which it would be possible to generalise findings.

\section{Results and discussion}

In SA, the pharmacy profession is currently dominated by women ${ }^{[11}$ and our study population $(N=786)$ reflected this trend. Of the 201 thirdyear students in 2012, 45 (22.4\%) were male, and of the 585 fourth-year students between 2007 and 2012, 151 (25.8\%) were male.

\section{MBTI $^{\circledR}$ preference distribution of fourth-year students from 2007 to 2012}

When we observed the individual preferences of the fourth-year students, it was found that there were significantly more who preferred Introversion, Sensing, Feeling and Judging than in the general SA population (Fig. 1). ${ }^{[12]}$ This indicated that the proportion of students with a preference for Feeling in the study population varied between $41 \%$ and $58 \%{ }^{[6]}$ i.e. at least $12 \%$ above the $28.3 \%$ reported in the SA population. ${ }^{[12]}$ There was a consistent over-representation of students with a preference for Feeling compared with the general population.

\section{MBTI $^{\circledR}$ preference distribution of third- and fourth-year students in 2012}

When comparing the preference distribution of the third-year students with that of the fourth-year students (Fig. 2), it was found that the preference distribution of the former followed the same pattern as that of the fourth-year students in 2012.

Both groups of 2012 students had preferences for Introversion, Sensing, Feeling and Judging compared with the general population in SA. These findings corroborate the analysis of the fourth-year students (2007 - 2012)

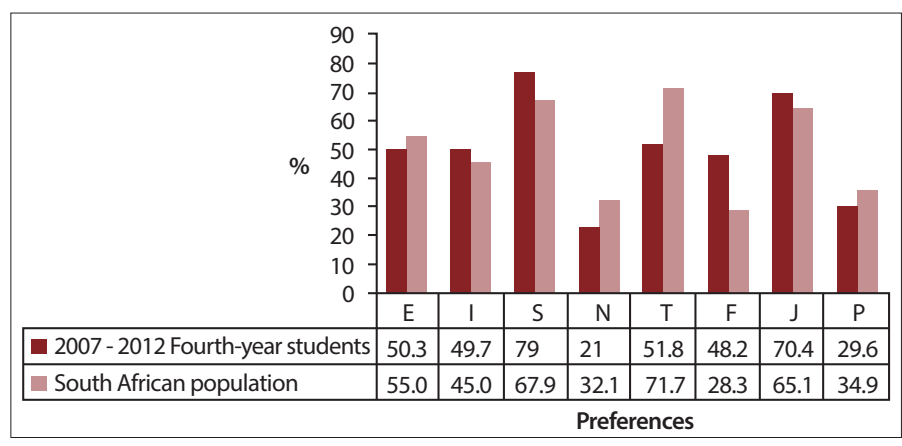

Fig. 1. Preference distribution for fourth-year students between 2007 and 2012 compared with that in the SA population. ${ }^{[12]}(E=$ Extroversion; $F=$ Feeling; $I=$ Introversion; $J=$ Judging; $N=$ Intuition; $P=$ Perceiving; $S=$ Sensing; $T$ = Thinking.)

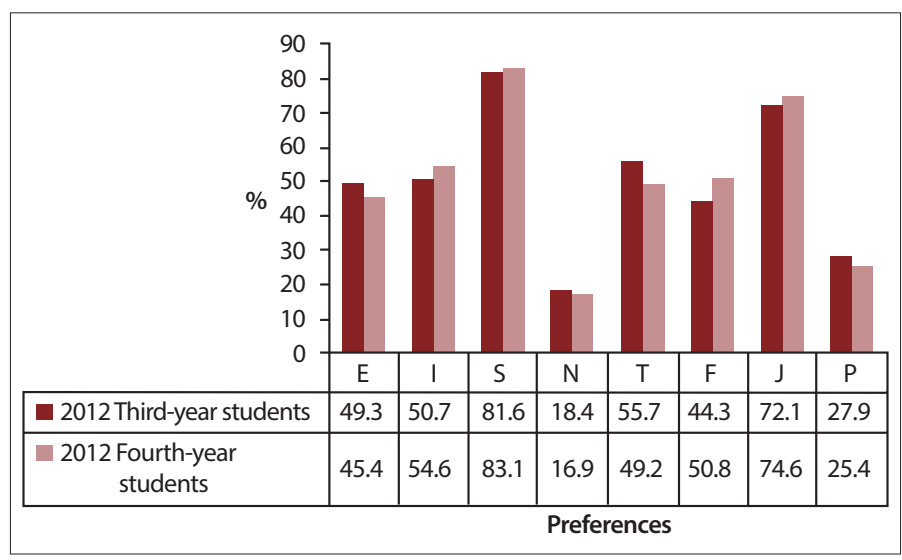

Fig. 2. Preference distribution for third-year students of 2012 compared with that of fourth-year students of 2012. ( $E=$ Extroversion; F = Feeling; $I=$ Introversion; $J$ = Judging; $N=$ Intuition; $P=$ Perceiving; $S=$ Sensing; $T$ = Thinking.) 


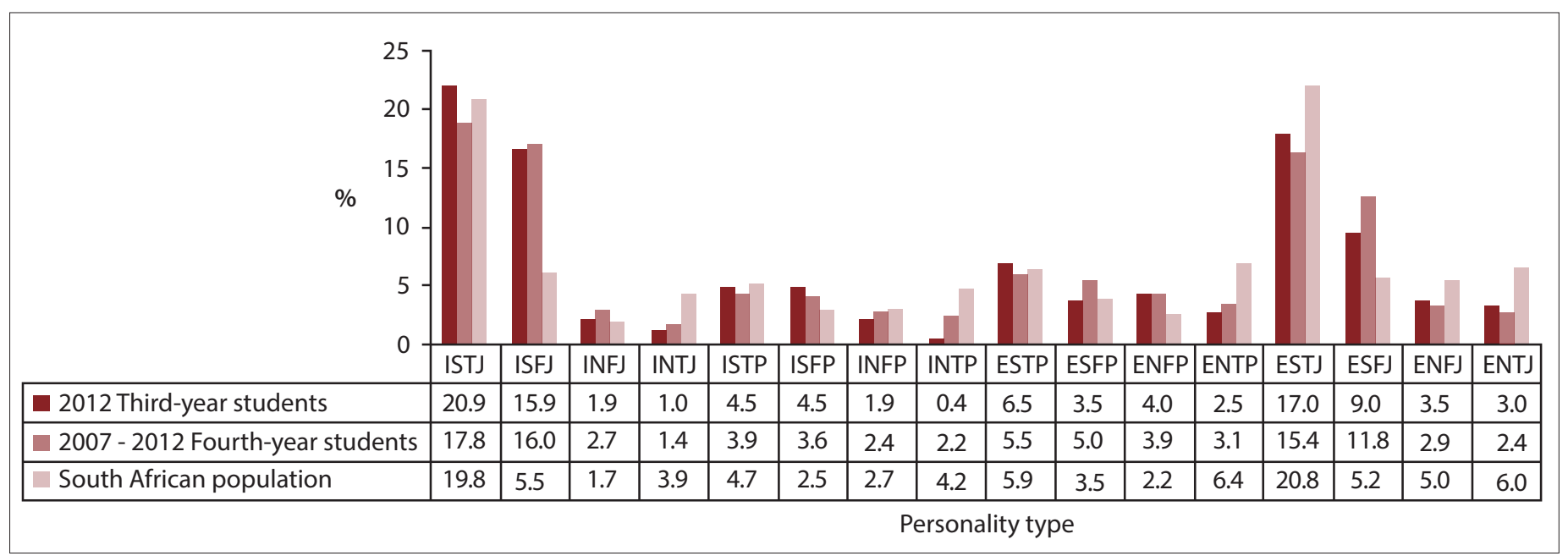

Fig. 3. The MBTI ${ }^{\circledR}$ personality type distribution of the 2007 - 2012 fourth-year and 2012 third-year study population compared with the SA population. ${ }^{[12]}$ (E $=$ Extroversion; F = Feeling; $I=$ Introversion; $J$ = Judging; $N=$ Intuition; $P=$ Perceiving; $S=$ Sensing; $T$ = Thinking.)

overall. The findings showed that there are consistently more students per year group with a preference for Sensing and/or Feeling in the study population compared with the general population since $2007 \cdot{ }^{[7]}$

\section{MBTI $^{\circledR}$ personality type distribution}

The MBTI ${ }^{\circledR}$ types most strongly represented in the 2007 - 2012 study population were ISTJ, ISFJ, ESTJ and ESFJ. Compared with the general population, it is clear that there were more ISFJs and ESFJs in the study population (Fig. 3). In the SA population the least represented type is ${ }^{I N F J}{ }^{[12]}$ among the 2012 third-year students it is INTP, and among the 2007 - 2012 fourth-year students it is INTJ.

\section{Probability that a like-minded student and patient will interact}

Probability was calculated using the values in Fig. 3. A fourth-year student with the greatest possibility of interacting with a like-minded patient is an ISTJ personality type (Fig. 4). Therefore, out of 10000 consultations that the ISTJ fourth-year student will conduct, only 352 are likely to be with an ISTJ patient. Participants who have the smallest chance (0.01\%) to interact with a patient of similar type are third-year INTP students in 2012, i.e. of 10000 consultations that the student will conduct, only one might be with a patient with an INTP preference.

The same pattern held for the entire fourth-year population over the six years and for the 2012 cohort of third-year students. The likelihood of pharmacy students interacting with patients with

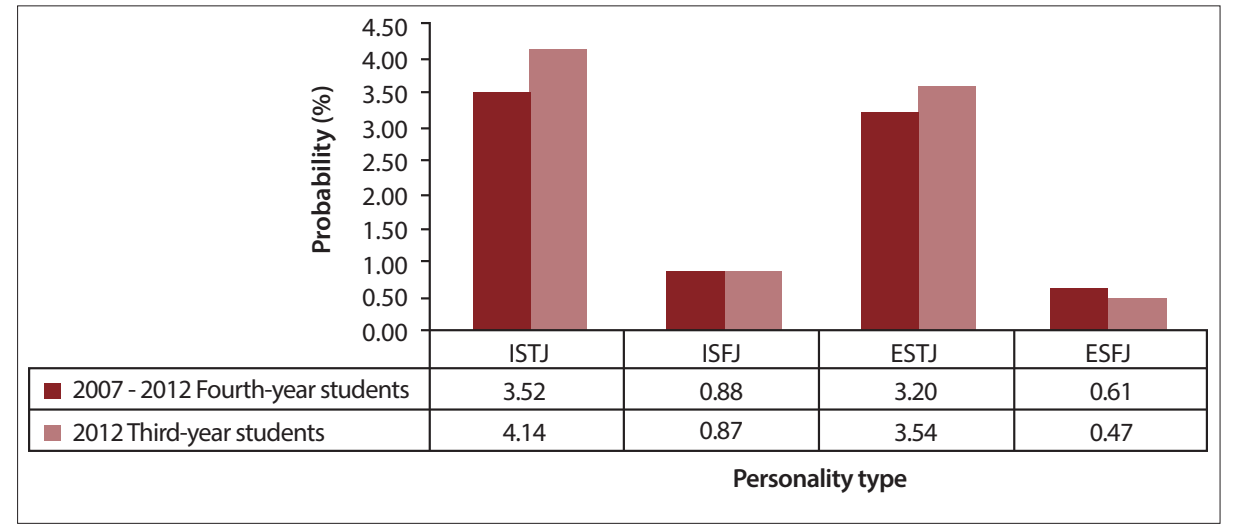

Fig. 4. The four personality types in the study population with the greatest possibility to interact with like-minded patients in SA. (E = Extroversion; F = Feeling; $I=$ Introversion; $J=$ Judging; $N=$ Intuition; $P=$ Perceiving; $S=$ Sensing; $T=$ Thinking.)

similar preferences varies between one and 414 chances in 10000 , emphasising the importance for a pharmacy student to be aware not only of his own communication style or preferences, but also of the expectations that patients with other styles are likely to have of pharmacists in a professional setting.

\section{Discussion}

For the first time in the communication training of pharmacy students at a higher education training institution, the personality type framework of Myers and Briggs was used to enable students to appreciate their own preferences and communication styles and those of others. ${ }^{[9]}$ During the first part of this project, it was shown that the MBTI ${ }^{\circledR}$ personality theory holds for pharmacy students, ${ }^{[7]}$ even though they have been trained in a health environment. Prompted by questions related to their professional practice, the students still responded habitually according to MBTI $^{\circledR}$ theory.

The entire study population, irrespective of year of study, favoured the Sensing-Feeling preferences. Compared with the SA population, it seems that a greater proportion of students at this pharmacy school tends to have SensingFeeling preferences, with the accompanying communication style implications. ${ }^{[13]}$

Patients with a preference for Sensing might prefer to focus on detail and facts during communication, are anchored in current realities and common sense, and immediately apply what is communicated. However, patients with a preference for Intuition might talk about possibilities and trends, are future orientated and may prefer to link and integrate information, ${ }^{[13]}$ e.g. students with a preference for Sensing who may focus on facts and details ${ }^{[7]}$ have to realise 
that some patients with a preference for Intuition may be interested in alternatives in a medication-related request.

It was established that there were consistently more students with a preference for Feeling than in the general population, which has positive implications for patient-centred care. Patient-centred care requires the pharmacist to be able to strengthen the relationship with the patient, improve the patient's knowledge about health, promote communication about important health-related matters and engage the patient to become involved in his own healthcare. ${ }^{[14]}$ Pharmacy students with a preference for Feeling may have a natural tendency to empathise and develop rapport with their patients; appreciate their patients' perspective; be supportive, nurturing and interested in their patients; and enjoy collaborating. ${ }^{[13]}$ Therefore, students with a preference for Feeling may be naturally orientated towards patient-centred care.

Such students need to realise that patients with a preference for Thinking might, for example, prefer objective, honest and frank feedback. These patients might prefer to debate and challenge medication information and request the pharmacist to list the pros and cons. ${ }^{[13]}$

In conclusion, even an ISTJ student among the fourth-year cohort, with the best chance of consulting with a like-minded patient, will not be attending to a patient with a similar personality type for $96.48 \%$ of the time. While some patients experience a specific behaviour as caring, others might experience it as non-caring. ${ }^{[15]}$ It seems that central to the patient's experience of patient-centred care is a set of pharmacist abilities, including seeing the patient's point of view. A pharmacist who is familiar with personality type theory has a better chance to understand a patient's experience. Pharmacists do not need to know the personality type of each patient; they only need to be aware of the different preferences and be sensitive to the associated implications.

\section{Recommendations}

The $\mathrm{MBTI}^{\circledR}$ can be used as a tool to address the patient-centred communication training of pharmacists to support the shift in educational focus. Such communication requires students to be aware not only of their own preferences and communication style, but also of the preferences of patients that are not similar to their own. This knowledge will help pharmacy students to grasp the world from the patient's perspective, especially in terms of what the patient regards as meaningful.

Although the majority of the students preferred Sensing-Feeling, they should be aware of and sensitive to the communication expectations of patients with preferences other than their own. Knowing about the behavioural and communication implications of the different $\mathrm{MBTI}^{\circledR}$ preferences may enable students to move nearer to the ideal of treating their patients with empathy, respect and unconditional regard.

Even though there is a very small chance for a pharmacy student to interact with a patient of similar MBTI ${ }^{\circledR}$ personality type, the former does not need to know what the personality type of each of their patients is; they only need to be aware of the different preferences and sensitive to the associated implications. Consequently, pharmacy students will recognise the legitimate needs and associated meanings in their patients' communication.

\section{Conclusion}

Knowing personality type will enhance the skills set needed by any pharmacist to address the specific requirements of patient-centredness. A broad understanding of the different preferences and associated communication style implications that the patient might have is key to recognising the different needs of patients.

\section{References}

1. Stewart M. Towards a global definition of patient centred care. BMJ 2011;322(7284):444-445. [http://dx.doi org $/ 10.1136 / \mathrm{bmj} .322 .7284 .444]$

. Dinsmoor R. What your pharmacist can do for you: A resource often overlooked. Asthma Magazine 2003:27-29. [http://dx.doi.org/10.1067/mas.2003.2]

3. Berenguer B, La Casa C, De La Matta MJ, Martin-Calero MJ. Pharmaceutical care: Past, present and future. Curr Pharm 2004;10(31):3931-3946.

4. Worley MM, Schommer JC, Brown LM, et al. Pharmacists' and patients' roles in pharmacist-patient relationship: Are pharmacists and patients reading from the same relationship script? Res Soc Adm Pharm 2007:3:47-69. [http://dx doi.org/10.1016/j.sapharm 2006.03.003]

[http.//dx.doi.oro 5. South African Pharmacy Council. Intern and Tutor Manual fo
Interns. Pretoria: South African Pharmacy Council, 2013:10-33.

. 6. Boesen KP, Herrier RN, Apgar DA, Jackowski RM. Improvisational exercises to improve pharmacy s
professional communication skills. Am J Pharm Educ 2009;73:35. [http://dx.doi.org/10.5688/aj730235] 7. Basson MJ, Eksteen MJ. Pharmacists, communication preferences and care. Prague, 2012. http:// www.inter-disciplinary.net/probing-the-boundaries/wp-content/uploads/2012/04/the-patient2 Mari\%C3\%ABttaBassonMarietEksteen-website-paper.pdf (accessed 26 November 2013).

8. Sims LM, Haines SL. Challenges of a pharmacist-directed peer support program among adolescents with diabetes. J Am Pharm Assoc 2003;51(6):766-769.

9. Myers IB, McCaulley MH. Manual: A Guide to the Development and Use of the Myers Briggs Type Indicator. 2nd ed. Palo Alto: Consulting Psychologists Press, 1985:1-309. [http://dx.doi.org/10.1331/ JAPhA.2011.10041]

10. Catley K, Tipler MJ. National Curriculum Mathematics. Level 6. Christchurch: Caxton Educational, 1997:125.

11. South African Pharmacy Council. Pharmacy Human Resources in South Africa. Pretoria: South African Pharmacy Council, 2011:34.

12. Taylor N, Yianrakis C. South African MBTI Form M Data Supplement. Johannesburg: Jopie van Rooyen and Partners, 2007:1-25.

Partners, 2007:1-25.
3. Dunning D. Introduction to Type and Communication. California: CPP, 2003:1-54

14. Epstein RM, Street RL. The values and value of patient-centered care. Ann Fam Med 2011;9(2):100-103. [http:// Epstein RM, Street RL. The val
dx.doi.org/10.1370/afm.1239]

15. Quirk M, Mazor K, Haley HL, et al. How patients perceive a doctor's caring attitude. Patient Educ Couns 2008;72:359-366. [http://dx.doi.org/10.1016/j.pec.2008.05.022] 